\title{
Sarcopenia is associated with increased severe postoperative complications after colon cancer surgery
}

Tolga Olmez ${ }^{1}$, Erdal Karakose ${ }^{1}$, Hilmi Bozkurt ${ }^{1}$, Halime Hanim Pence ${ }^{2}$, Selcuk Gulmez ${ }^{1}$, Emre Aray ${ }^{1}$, Can Ibrahim Bulut ${ }^{1}$, Ozlem Zeliha Sert ${ }^{1}$, Erdal Polat ${ }^{1}$, Mustafa Duman ${ }^{1}$

${ }^{1}$ Department of Gastroenterological Surgery, Kartal Kosuyolu High Speciality
and Training Hospital, University of Health Sciences, Istanbul, Turkey
${ }^{2}$ Department of Biochemistry, University of Health Sciences, Istanbul, Turkey

Submitted: 11 July 2019; Accepted: 12 September 2019;

Online publication: 9 October 2019

Arch Med Sci 2021; 17 (2): 361-367

DOI: https://doi.org/10.5114/aoms.2019.88621

Copyright $\odot 2019$ Termedia \& Banach

\section{Abstract}

Introduction: Studies have shown that sarcopenia is associated with poor outcomes in patients with gastrointestinal cancer undergoing surgery. We aimed to investigate the relationship between postoperative complications of sarcopenic patients who had been operated on for colon cancer and the effects on short-term mortality.

Material and methods: In this study, patients who had undergone colon cancer surgery between January 2013 and December 2018 were collected retrospectively. Sarcopenia was diagnosed by the skeletal muscle index (SMI) derived from a preoperative computed tomography scan. Multiple logistic regression analysis was performed to determine whether sarcopenia is associated with postoperative major complications (POMC).

Results: The study included 160 patients with a mean age of $62.4 \pm 12.6$ years. Clavien-Dindo grade 1-2 (minor) complications were not significantly different between the groups $(p=0.896)$. However, grade $\geq 3$ (major) complications were detected in $13(17.8 \%)$ patients in the sarcopenic group (SG) and in 5 patients in the non-sarcopenic group (NSG) $(5.7 \%)(p=0.016)$. Length of intensive care unit (ICU) stay was longer in SG $(p=0.002)$ and there was no difference between 1-month and 6-month mortality rates $(p=0.273$ and $p=0.402$, respectively). According to univariate analyses, sarcopenia and age over 65 years were related to POMC. In multivariate analyses, sarcopenia (odds ratio $=3.039 ; 95 \%$ confidence interval 1.008-9.174; $p=0.048$ ) and advanced age (odds ratio $=3.246$; $95 \%$ confidence interval 1.078-9.803; $p=0.036$ ) were found to be independent risk factors for POMC.

Conclusions: This study showed that while sarcopenia is a risk factor for POMC, sarcopenia also prolongs the duration of ICU stay. Also sarcopenia has no effect on short-term mortality.

Key words: colon cancer, sarcopenia, complication postoperative.

\section{Introduction}

According to the European Working Group on Sarcopenia in Older People, sarcopenia is a syndrome that causes progressive and generalized skeletal muscle loss, and is related to poor quality of life, physical limitation and death. Although this condition often comes with aging, many other causes have been identified, such as malnutrition, immobility, inflammatory disease and cancer, all of which can be detected at any age [1].

\author{
Corresponding author: \\ Tolga Olmez \\ Gastrointestinal \\ Surgery Fellow \\ Denizer caddesi \\ Kartal Kosuyolu \\ High Speciality and \\ Training Hospital \\ 34865 Istanbul, Turkey \\ Phone: +90 5327631058 \\ Fax: +90 2164596321 \\ E-mail: tolgaolmez@gmail. \\ com
}


Several methods have been developed for evaluation of muscle strength, muscle mass and physical performance in the diagnosis of sarcopenia. The method of measuring psoas muscle area in computed tomography (CT) has gained popularity in recent years due to its practicality [2]

The prevalence of colorectal cancer is increasing throughout the world, with the primary treatment approach still being surgery. The associated complications have always been a significant cause of morbidity, and there have been several studies identifying various factors that promote the development of complications after colorectal cancer surgery $[3,4]$.

In recent years, studies have found sarcopenia to be associated with a poor prognosis after surgery for gastrointestinal system cancers [5-7]. According to these studies, sarcopenia causes increases in the rates of postoperative general complications and the length of hospital stay, and decreases in disease-free survival and overall survival rates. Severe postoperative complications may prolong the length of hospitalization and the healing process, may delay postoperative adjuvant therapy, and may shorten life expectancy $[8,9]$. In the present study we investigate the relationship between postoperative complications and sarcopenia in patients who have been operated on for colon cancer, along with the effects on short-term mortality.

\section{Material and methods}

Adopting a retrospective study design, this study reviews the data of patients who underwent colon cancer surgery in the gastroenterologic surgery clinic. Approval for the study was obtained from the ethics committee of the hospital in which the study was conducted (numbered 2019.2/11-162), and the study was carried out in accordance with the ethical standards of the Helsinki Declaration (revised in 2013). A review was made of patient files in the hospital archive from January 2013 to December 2018. Patients aged 18 years of age or older who underwent elective surgery due to a colon or rectosigmoid tumor, and who were identified with an Eastern Cooperative Oncology (ECOG) status of $\leq 2$, were included in the study. The exclusion criteria were: patients with a pathology other than adenocarcinoma, those who have undergone an R1/R2 resection, those operated on for palliative purposes, those with no abdominal CT from within the last preoperative month, those requiring additional organ resections (excluding liver metastasectomy) and those undergoing emergency surgery to avoid increasing the number of anastomoses. Also excluded from the study were the 18 patients whose preoperative CT images could not be accessed.
The patients were divided into two groups, as sarcopenic or non-sarcopenic. The demographic data, postoperative complications and short-term mortality of all patients were compared between the two groups. Height-weight measurements in the final week, body mass index $\left(\mathrm{BMI} \geq 25 \mathrm{~kg} / \mathrm{m}^{2}\right.$ accepted as obese), carcinoembryonic antigen (CEA), hematocrit (hct) level, albumin levels and alcohol use were recorded. Those who had used cigarettes in the last 1 month were defined as active smokers, and the patients who regularly consumed alcohol were also recorded. Focusing on the magnitude of stress-induced inflammation and the ability of the patient to generate an adequate host response has led to the concept of "immunonutrition" [10]. Those who were administered immunonutrition orally for 5 days preoperatively and postoperatively, in line with the application protocol of our clinic and as recommended in the guidelines $[10,11]$. Immunonutrition contained daily glutamine ( $20 \mathrm{~g})$, arginine ( $4.3 \mathrm{~g})$, RNA $(0.43 \mathrm{~g}), \Omega-3$ fatty acids (1.4 g) and antioxidants in the form of a standard oral enteral nutrition for each repast.

Patients who had undergone abdominal surgery for any reason or neoadjuvant chemotherapy were recorded. The Charlson comorbidity index $(\mathrm{CCl})$ was used to define comorbidities [12]. Length of stay in the intensive care unit (ICU), dates of hospital admissions, preoperative ejection fraction (EF) values, Nutritional Risk Screening (NRS-2002) scores, ASA (American Society of Anesthesiologists) grades, comorbidities of patients, tumor localizations (right colon; cecum, ascending colon, $1 / 3$ proximal transverse colon and left colon; 2/3 distal transverse colon, descending colon, sigmoid colon, rectosigmoid junction), type and duration of operations and postoperative complications were all recorded. The patients were staged according to the $8^{\text {th }}$ edition of the American Joint Committee on Cancer (AJCC) Colon and Rectum Staging Manual.

Diagnoses of sarcopenia were made from preoperative CT imaging studies. The areas of both psoas muscles in the cross-sectional view, where both transverse processes were seen at the lumbar 3 (L3) vertebrae level, were measured and recorded by the consultant radiologist

The Hounsfield unit scale $(-29$ to +150$)$ was used to identify skeletal muscles from other structures, and the calculated total area was proportional to the square of the patient's height. According to international consensus, a skeletal muscle index (SMI) of $<545 \mathrm{~mm}^{2} / \mathrm{m}^{2}$ in men and $<385 \mathrm{~mm}^{2} / \mathrm{m}^{2}$ in women indicates sarcopenia [12].

All operations were performed by gastroenterologic surgeons. Postoperative complications and short-term mortality data was also recorded. 
Complications were classified according to the Clavien-Dindo classification system [13], according to which groups $1-2$ have minor and $\geq 3$ have major complication rates.

Additionally, 1-month and 6-month mortality rates were also calculated.

\section{Statistical analysis}

Normally distributed continuous data were presented as mean \pm standard deviation (SD), while categorical variables were given as numbers and percentages. Clinical variables were compared with Student's $t$-test and the Pearson $\chi^{2}$ test. The effect of sarcopenia on postoperative complications was evaluated with univariate and multivariate logistic regression analyses. The multivariate logistic regression analysis was performed in univariate analyses with $p<0.1$ and $p<0.05$ was considered statistically significant in all tests. All statistical analyses were performed using the SPSS statistics program, version 25.0 (IBM, Armonk, NY).

\section{Results}

A total of 160 patients who underwent colon cancer surgery, and whose CT imaging could be accessed, were included in the study, of whom 93 (58.1\%) were male. According to SMI calculations, $73(45.6 \%)$ of the patients were sarcopenic and 87 (54.4\%) were not. Furthermore, $45.1 \%$ of the male patients and $46.2 \%$ of the female patients were sarcopenic. Figure 1 shows the distribution of SMI according to sex. SMI and total psoas area (TPA) were both found to be associated with sarcopenia ( $p<0.001$ and $p<0.001$, respectively). The demographic and clinical characteristics of the patients and the results of the comparison of the sarcopenic group (SG) and the non-sarcopenic group (NSG) are presented in Table I. No statistically significant differences were noted between the groups in terms of factors that may be associated with postoperative complications. Tumors frequently originated from the left side of the colon (64.3\%), and 7 patients underwent a simultaneous liver metastasectomy (R0) with a colon resection. Data on the pathological stages and other pathological findings are given in Table II.

The number of Clavien-Dindo grade 1-2 (minor) complications was not significantly different between the two groups ( $p=0.896)$. However, grade $\geq 3$ (major) complications were detected in $13(17.8 \%)$ patients in the SG and in $5(5.7 \%)$ patients in the NSG, and the difference was statistically significant $(p=0.016)$. The lengths of ICU and hospital stays were longer in the SG, but only the length of ICU stays was statistically significant $(p=0.002)$. Although the rates of postoper-

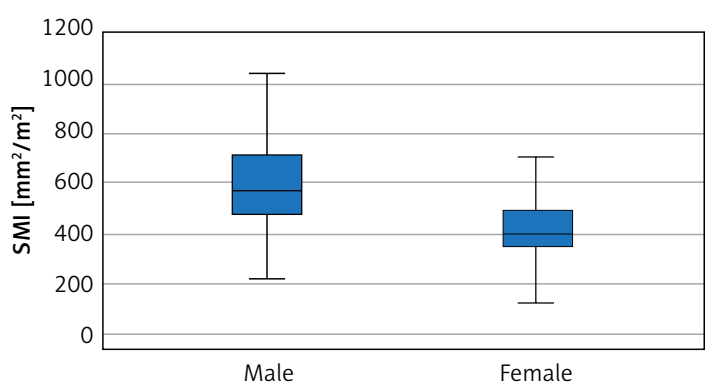

Figure 1. Boxplot Showing Skeletal Muscle Index (SMI) classified by sex

ative major complications (POMC) were different, no significant difference was identified between 1 -month and 6-month mortality rates ( $p=0.273$ and $p=0.402$, respectively) (Table III).

Surgical site infections and anastomotic leaks requiring surgery or percutaneous drainage catheter application were found to be the most common complications in both groups (SG $=6 / 6$ and NSG $=2 / 1$ patients, respectively), with other major complications being postoperative ileus (NSG = 1 patient) and arterial embolism (SG $=1$ patient). One patient in the non-sarcopenic group died of acute renal failure postoperatively.

The major postoperative complications were investigated. According to the univariate analyses, sarcopenia $(\mathrm{OR}=3.558 ; 95 \% \mathrm{Cl}$ : 1.201-10.526; $p=0.022)$ and age > 65 years $(\mathrm{OR}=3.759$; $95 \% \mathrm{Cl}: 1.273-11.111 ; p=0.017)$ are related to POMC. In the multivariate analyses, sarcopenia $(\mathrm{OR}=3.039 ; 95 \% \mathrm{Cl}: 1.008-9.174 ; p=0.048)$ and advanced age $(\mathrm{OR}=3.246 ; 95 \% \mathrm{Cl}$ : 1.078-9.803; $p=0.036)$ were found to be independent risk factors for POMC (Table IV).

\section{Discussion}

Although there have been advances in surgical approaches and perioperative care related to colon cancer, major postoperative complications remain an important cause of morbidity and mortality. Several studies conducted in recent years have found sarcopenia to be associated with short- and long-term adverse outcomes [14-16].

In this study, we excluded rectum tumors to allow the creation of homogeneous groups. The stage 4 patients were all synchronized liver metastasis patients, therefore excluding more expansive surgeries such as cytoreductive surgery and hyperthermic intraperitoneal chemotherapy. An analysis of the group distributions revealed similar surgeries in the sarcopenic and non-sarcopenic groups.

This study has shown that sarcopenia is associated with poor outcomes following colon cancer surgery. The general POMC rate was $11.2 \%$, which is similar to the rate reported in previous studies $[17,18]$. 
Table I. Demographic and clinical characteristics of sarcopenic and non-sarcopenic patients who underwent curative surgery for colon adenocarcinoma

\begin{tabular}{|c|c|c|c|c|}
\hline Parameter & $\begin{array}{c}\text { Total } \\
(n=160)\end{array}$ & $\begin{array}{l}\text { Sarcopenic } \\
(n=73)\end{array}$ & $\begin{array}{l}\text { Non-sarcopenic } \\
\quad(n=87)\end{array}$ & $P$-value \\
\hline Age [years], mean \pm SD & $62.4 \pm 12.6$ & $66.03 \pm 10.7$ & $59.38 \pm 13.4$ & 0.55 \\
\hline \multicolumn{5}{|l|}{ Gender, $n(\%)$ : } \\
\hline Male & $93(58.1)$ & $42(57.5)$ & $51(58.6)$ & \\
\hline Female & $67(41.9)$ & $31(42.5)$ & $36(41.4)$ & \\
\hline $\mathrm{BMI}\left[\mathrm{kg} / \mathrm{m}^{2}\right]$, mean $\pm \mathrm{SD}$ & $27.8 \pm 4.5$ & $26.9 \pm 4.5$ & $28.5 \pm 4.4$ & 0.91 \\
\hline $\mathrm{SMI}\left[\mathrm{mm}^{2} / \mathrm{m}^{2}\right]$, mean $\pm \mathrm{SD}$ & $516.7 \pm 194.0$ & $377.3 \pm 111.1$ & $633.6 \pm 170.2$ & $<0.001$ \\
\hline TPA $\left[\mathrm{mm}^{2}\right]$, mean \pm SD & $1433.5 \pm 599.4$ & $1076.0 \pm 387.4$ & $1733.5 \pm 582.3$ & $<0.001$ \\
\hline ASA grade, $n(\%):$ & & & & 0.82 \\
\hline 1 & $3(1.8)$ & $1(1.3)$ & $2(2.2)$ & \\
\hline 2 & $47(29.3)$ & $21(28.7)$ & $26(29.8)$ & \\
\hline 3 & $101(63.1)$ & $48(65.7)$ & $53(60.9)$ & \\
\hline 4 & $9(5.6)$ & $3(4.1)$ & $6(6.8)$ & \\
\hline $\mathrm{EF}, n(\%):$ & & & & 0.79 \\
\hline$<50$ & $5(3.1)$ & $2(2.7)$ & $3(3.4)$ & \\
\hline$\geq 50$ & $155(96.9)$ & $71(97.3)$ & $84(96.6)$ & \\
\hline $\mathrm{CCl}, n(\%):$ & & & & 0.16 \\
\hline$\geq 2$ & $20(12.5)$ & $12(16.4)$ & $8(9.1)$ & \\
\hline$<2$ & $140(87.5)$ & $61(83.5)$ & 79 (90.9) & \\
\hline Smoker, $n(\%)$ & $40(25)$ & $14(19.1)$ & $26(29.8)$ & 0.13 \\
\hline Alcohol, $n$ (\%) & $6(3.7)$ & $3(4.1)$ & $3(3.4)$ & 0.82 \\
\hline $\begin{array}{l}\text { Abdominal operation } \\
\text { history, } n(\%)\end{array}$ & $39(24.3)$ & $18(24.6)$ & $21(24.1)$ & 0.93 \\
\hline $\begin{array}{l}\text { Chemotherapy history, } \\
n(\%)\end{array}$ & $3(1.8)$ & $1(1.3)$ & $2(2.2)$ & 0.66 \\
\hline NRS-2002 score, $n(\%)$ : & & & & 0.21 \\
\hline $0-1$ & $149(93.2)$ & $66(90.5)$ & $83(95.5)$ & \\
\hline$\geq 2$ & $11(6.8)$ & $7(9.5)$ & $4(4.5)$ & \\
\hline $\begin{array}{l}\text { Perioperative } \\
\text { immunonutrition, } n(\%)\end{array}$ & $76(47.5)$ & $32(43.8)$ & $44(50.5)$ & 0.39 \\
\hline $\begin{array}{l}\text { Preoperative hematocrit } \\
(\%), \text { mean } \pm \text { SD }\end{array}$ & $34.67 \pm 5.96$ & $34.32 \pm 5.42$ & $34.87 \pm 6.40$ & 0.19 \\
\hline $\begin{array}{l}\text { Preoperative CEA [ng/ml], } \\
n(\%)\end{array}$ & & & & 0.19 \\
\hline$\geq 5$ & $50(31.2)$ & $19(26.0)$ & $31(35.6)$ & \\
\hline $0-5$ & $110(68.8)$ & $54(74.0)$ & $56(64.4)$ & \\
\hline $\begin{array}{l}\text { Albumin }[\mathrm{g} / \mathrm{l}] \text {, mean } \pm \mathrm{SD} \\
\text { (normal range: } 3.5-5.2 \text { ) }\end{array}$ & $4.04 \pm 0.52$ & $3.97 \pm 0.62$ & $4.09 \pm 0.42$ & 0.24 \\
\hline
\end{tabular}

Values are presented as mean \pm SD (standard deviation) or $n$ (\%). Preoperative BMI - body mass index, SMI - skeletal muscle index, TPA - total psoas area, ASA - American Society of Anesthesiologists, EF- ejection fraction, CCI - Charlson comorbidity index, NRS-2002 Nutritional Risk Screening-2002, CEA - carcinoembryonic antigen are presented.

Of the 18 patients who suffered severe complications, one in the non-sarcopenic group died of acute renal failure within 30 postoperative days. The most common major com- plications were surgical site infection and anastomotic leakage in both groups, and this frequency was similar to some previously published studies [18]. 
Table II. Operation and pathology findings of the patients

\begin{tabular}{|c|c|c|c|c|}
\hline Parameter & $\begin{array}{c}\text { Total } \\
(n=160)\end{array}$ & $\begin{array}{l}\text { Sarcopenic } \\
(n=73)\end{array}$ & $\begin{array}{c}\text { Non-sarcopenic } \\
(n=87)\end{array}$ & $P$-value \\
\hline Tumor side, $n(\%)$ : & & & & 0.50 \\
\hline Right colon & $57(35.6)$ & $24(32.8)$ & $33(37.9)$ & \\
\hline Left colon & $103(64.4)$ & $49(67.2)$ & $54(62.1)$ & \\
\hline Operation type, $n$ (\%) & & & & 0.11 \\
\hline Anterior resection & $42(26.2)$ & $20(27.4)$ & $19(21.8)$ & \\
\hline Low anterior resection & $22(13.7)$ & $8(10.9)$ & $13(14.9)$ & \\
\hline $\begin{array}{l}\text { Low anterior resection + } \\
\text { loop ileostomy }\end{array}$ & $10(6.2)$ & $6(8.2)$ & $3(3.5)$ & \\
\hline Right hemicolectomy & $58(36.2)$ & $24(32.9)$ & $33(37.9)$ & \\
\hline Left hemicolectomy & $19(11.8)$ & $4(5.5)$ & $14(16)$ & \\
\hline Subtotal colectomy & $5(3.1)$ & $4(5.5)$ & $1(1.2)$ & \\
\hline Total colectomy & $1(0.6)$ & 0 & $1(1.2)$ & \\
\hline Transverse colectomy & $3(1.8)$ & $3(4.1)$ & 0 & \\
\hline $\begin{array}{l}\text { Colon resection }+ \\
\text { metastasectomy }\end{array}$ & $7(4.4)$ & $4(5.5)$ & $3(3.5)$ & \\
\hline Laparoscopic surgery, $n$ (\%) & $44(27.5)$ & $18(24.6)$ & $26(29.8)$ & 0.46 \\
\hline $\begin{array}{l}\text { Operation time [min], } \\
\text { mean } \pm \text { SD }\end{array}$ & $207.8 \pm 64.9$ & $199.6 \pm 64.2$ & $214.6 \pm 65.1$ & 0.79 \\
\hline Pathologic stage, $n(\%)$ : & & & & 0.23 \\
\hline 0 & $2(1.3)$ & 0 & $2(2.2)$ & \\
\hline 1 & $22(13.7)$ & $8(10.9)$ & $14(16.0)$ & \\
\hline 2 & $73(45.6)$ & $39(53.4)$ & $34(39.0)$ & \\
\hline 3 & $56(35.0)$ & $22(30.1)$ & $34(39.0)$ & \\
\hline 4 & $7(4.4)$ & $4(5.4)$ & $3(3.4)$ & \\
\hline $\begin{array}{l}\text { Lymphovascular invasion, } \\
n(\%)\end{array}$ & $59(36.8)$ & $25(34.2)$ & $34(39.0)$ & 0.52 \\
\hline Perineural invasion, $n$ (\%) & $41(25.6)$ & $21(28.7)$ & $20(22.9)$ & 0.40 \\
\hline$N \geq 1(\%)$ & $63(39.3)$ & $26(35.6)$ & $37(42.5)$ & 0.37 \\
\hline $\begin{array}{l}\text { Number of retrieved LNs; } \\
\text { mean } \pm \text { SD }\end{array}$ & $21.9 \pm 10.2$ & $22.2 \pm 11.0$ & $21.6 \pm 9.6$ & 0.61 \\
\hline
\end{tabular}

$N$ - pathologically positive lymph node(s), LNs - lymph nodes.

Table III. Postoperative complications, hospitalization and mortality information

\begin{tabular}{|lcccc|}
\hline Parameter & $\begin{array}{c}\text { Total } \\
(n=160)\end{array}$ & $\begin{array}{c}\text { Sarcopenic } \\
(n=73)\end{array}$ & $\begin{array}{c}\text { Non-sarcopenic } \\
(n=87)\end{array}$ & $P$-value \\
\hline Grade 1-2 (minor), $n(\%)$ & $78(48.7)$ & $36(49.3)$ & $42(48.2)$ & $5(5.7)$ \\
\hline $\begin{array}{l}\text { Grade } \geq 3 \text { (major), } n(\%) \\
\text { Length of hospital stay }\end{array}$ & $18(11.2)$ & $13(17.8)$ & $9.89 \pm 6.19$ & 0.094 \\
\hline $\begin{array}{l}\text { Length of intensive care } \\
\text { unit stay [day], mean } \pm \text { SD }\end{array}$ & $1.05 \pm 0.24 \pm 6.67$ & $11.55 \pm 7.14$ & $1.02 \pm 0.15$ & 0.002 \\
\hline 1 month mortality, $n(\%)$ & $1(0.6)$ & $1.09 \pm 0.32$ & 0 & 0.273 \\
\hline 6 months mortality, $n(\%)$ & $4(2.5)$ & $1(1.3)$ & $3(3.4)$ & 0.402 \\
\hline
\end{tabular}


T. Olmez, E. Karakose, H. Bozkurt, H. Hanim Pence, S. Gulmez, E. Aray, C.I. Bulut, O. Zeliha Sert, E. Polat, M. Duman

Table IV. Univariate and multivariate analysis of risk factors of major postoperative complications

\begin{tabular}{|c|c|c|c|c|c|c|}
\hline \multirow[t]{2}{*}{ Parameter } & \multicolumn{3}{|c|}{ Univariate } & \multicolumn{3}{|c|}{ Multivariate } \\
\hline & OR & $95 \% \mathrm{Cl}$ & $P$-value & OR & $95 \% \mathrm{Cl}$ & $P$-value \\
\hline Sarcopenia (yes/no) & 3.558 & $\begin{array}{l}1.201- \\
10.526\end{array}$ & 0.022 & 3.039 & $1.008-9.174$ & 0.048 \\
\hline Age $(\geq 65 /<65$ years $)$ & 3.759 & $\begin{array}{l}1.273- \\
11.111\end{array}$ & 0.017 & 3.246 & $1.078-9.803$ & 0.036 \\
\hline Gender (male/female) & 1.449 & $0.542-3.875$ & 0.460 & & & \\
\hline $\mathrm{BMI}(\geq 25 /<25)\left[\mathrm{kg} / \mathrm{m}^{2}\right]$ & 1.960 & $0.613-6.289$ & 0.256 & & & \\
\hline $\mathrm{CCl}(\geq 2 /<2)$ & 1.470 & $0.385-5.617$ & 0.572 & & & \\
\hline ASA grade $(\geq 3 /<3)$ & 2.475 & $0.682-8.928$ & 0.168 & & & \\
\hline $\begin{array}{l}\text { Perioperative } \\
\text { immunonutrition (yes/no) }\end{array}$ & 1.149 & $0.428-3.080$ & 0.783 & & & \\
\hline NRS-2002 $(<2 / \geq 2)$ & 1.288 & $\begin{array}{l}0.155- \\
10.695\end{array}$ & 0.815 & & & \\
\hline Albumin $(<3.5 / \geq 3.5 \mathrm{~g} / \mathrm{l})$ & 2.380 & $0.597-9.523$ & 0.219 & & & \\
\hline Pathologic stage $(0-1 / \geq 2)$ & 1.466 & $0.314-6.849$ & 0.626 & & & \\
\hline
\end{tabular}

Although complications have been treated, the duration of ICU stay was longer in the SG ( $p=$ 0.002). The length of hospitalization, on the other hand, was longer in the SG, but not to a statistically significant degree $(p=0.094)$, which agrees with the results of several previous studies $[19,20]$.

On the other hand, advanced age was found to be an independent risk factor for POMC in a multivariate analysis. Tamagava et al., in a study of 82 elderly patients, found sarcopenia to be an independent risk factor for postoperative complications in patients undergoing colorectal cancer surgery at an advanced age [21]. Poor nutrition or cachexia and muscle mass loss related to cancer can be seen in all age groups. That said, since advanced age is a risk factor for muscle mass loss, we considered it normal for the average age of the sarcopenic group in our study to be high.

Measurement of the psoas muscle at the L3 vertebra level has practical importance in the diagnosis of sarcopenia, and is considered reliable [17]. Margadant et al. reported that in a study of 373 patients, major complications after colorectal cancer surgery were more frequent in the sarcopenic group. In that study, sarcopenia diagnoses were based on the measurement of the psoas muscle thickness at the L3 vertebral level [22], and this reliable method was also adopted in the present study.

At the beginning of the study, the effect of perioperative immunonutrition supplementation on the results was curious. The perioperative use of regular immunonutrition was similar between the sarcopenic and non-sarcopenic groups ( $p=0.39$ ), although immunonutrition was not an independent risk factor for POMC. POMC was seen in
$21.8 \%$ of patients in the SG who were on immunonutrition and in $14.6 \%$ of those who were not, while in the NSG, these rates were $2.2 \%$ and $9.3 \%$ respectively. As a result, it is apparent that immunonutrition was more effective in the NSG. As mentioned in previous studies, the effect of immunonutrition on such complications as surgical site infection should be evaluated $[10,23]$. In addition to immunonutrition, sex, obesity, high $\mathrm{CCl}$, high ASA score, low NRS, low albumin level or advanced pathological stage would seem not to be independent risk factors for major complications.

According to a study by Nakanishi of 494 colorectal cancer patients, sarcopenia increases grade $\geq 2$ complications ( $p=0.0007$ ) and prolongs the duration of hospitalization $(p=0.02)$ [24]. In our study, sarcopenia caused an increase in grade $\geq 3$ complications $(p=0.016)$ but did not cause a statistically significant increase in the length of hospital stay ( $p=0.094)$.

According to the results of a meta-analysis published by Hajibandeh, sarcopenia has been shown to cause a significant rise in 30-day mortality after elective abdominal surgery [25]. Although major complications in the sarcopenic group were high in the present study, the mortality rates were similar for both groups (1- and 6-month mortality rates). The approach to the management of complications, such as surgical field infections and anastomotic leakage, should be considered as the cause.

The main limitation of this study is its retrospective, single-center study design. Although retrospective, some data were collected prospectively, and while the follow-up strategy did not change, parameters such as grip strength, walking 
speed and fatigue were not evaluated. The 18 patients with no CT imaging records from the 30-day preoperative period were excluded from the study, and could not be evaluated for sarcopenia. A reduction of complications could be targeted in prospective studies involving wider patient groups. Another limitation of the study is that the skeletal muscle index was not determined by the cut-off value. While we could have determined a cut-off value, the significant difference between race, sex and age groups for sarcopenia led to the study being conducted with a universal value.

This single-center study has shown that while sarcopenia is not a risk factor for postoperative minor complications following colon cancer surgery, it is an important risk factor for major complications, and sarcopenia also prolongs the duration of ICU stays. We believe that it has no effect on short-term mortality, but suggest that studies should be conducted into reducing postoperative morbidity in this group of sarcopenia patients, in which there is an increasing incidence with age.

\section{Conflict of interest}

The authors declare no conflict of interest.

\section{References}

1. Cruz-Jentoft AJ, Baeyens JP, Bauer JM, et al. Sarcopenia: European consensus on definition and diagnosis: report of the European Working Group on sarcopenia in older people. Age Ageing 2010; 39: 412-23.

2. Cruz-Jentoft AJ, Bahat G, Bauer J, et al. Sarcopenia: revised European consensus on definition and diagnosis. Age Ageing 2019; 48: 16-31.

3. Furnes B, Storli KE, Forsmo HM, et al. Risk factors for complications following introduction of radical surgery for colon cancer: a consecutive patient series. Scand J Surg 2019; 108: 144-51.

4. Cienfuegos JA, Baixauli J, Beorlegui C, et al. The impact of major postoperative complications on long-term out comes following curative resection of colon cancer. J Surg 2018; 52: 303-8.

5. Choi MH, Oh SN, Lee IK, et al. Sarcopenia is negatively associated with long-term outcomes in locally advanced rectal cancer. J Cachexiasarcopenia Muscle 2018; 9: 53-9.

6. Boer BC, de Graaff F, Brusse-Keizer M, et al. Skeletal muscle mass and quality as risk factors for postoperative outcome after open colon resection for cancer. Int J Colorectal Dis 2016; 31: 1117-24.

7. Lieffers JR, Bathe OF, Fassbender K, Winget M, Baracos VE. Sarcopenia is associated with postoperative infection and delayed recovery from colorectal cancer resection surgery. Br J Cancer 2012; 107: 931-6.

8. Vanvledder MG, Levolger S, Ayez N, Verhoef C, Tran TC, Ljzermans JN. Body composition and outcome in patients undergoing resection of colorectal liver metastases. Br J Surg 2012; 99: 550-7.

9. Prado CM, Lieffers JR, MC Cargar LJ, et al. Prevalence and clinical implications of sarcopenic obesity in patients with solid tumours of the respiratory and gastrointesti- nal tracts: a population-based study. Lancet Oncol 2008; 9: 629-35.

10. Weimann A, Braga M, Carli F, et al. ESPEN guideline: clinical nutrition in surgery. Clin Nutr 2017; 36: 623-50.

11. Marimuthu K, Varadhan KK, Ljungqvist O, Lobo DN, A meta-analysis of the effect of combinations of immunemodulating nutrients on outcome in patients undergoing major open gastrointestinal surgery. Ann Surg 2012; 255: 1060-8.

12. Fearon K, Strasser F, Anker SD, et al. Definition and classification of cancer cachexia: an international consensus. Lancet Oncol 2011; 12: 489-95.

13. Clavien PA, Barkun J, de Oliveira ML, et al. The ClavienDindo classification of surgical complications: five-year experience. Ann Surg 2009; 250: 187-96.

14. Umetsu S, Wakiya T, Ishido K, et al. Effect of sarcopenia on the out comes after pancreaticoduodenectomy for distal cholangiocarcinoma. ANZ J Surg 2018; 88: E654-8.

15. Yassaie SS, Keane C, French SJH, Al-Herz FAJ, Young MK, Gordon AC. Decreased total psoas muscle area after neoadjuvant therapy is a predictor of increased mortality in patients undergoing oesophageal cancer resection. ANZ J Surg 2019; 89: 515-9.

16. Anker MS, von Haehling S, Springer J, Banach M, Anker SD. Highlights of mechanistic and therapeutic cachexia and sarcopenia research 2010 to 2012 and their relevance for cardiology. Arch Med Sci 2013; 9: 166-71.

17. Jones KI, Doleman B, Scott S, Lund JN, Williams JP. Simple psoas cross-sectional area measurement is a quick and easy method to assess sarcopenia and predicts major surgical complications. Colorectal Dis 2015; 17 : 020-6.

18. Killingback M, Barron P, Dent O. Elective resection and anastomosis for colorectal cancer: a prospective audit of mortality and morbidity 1976-1998. ANZ J Surg 2002; 72: 689-98.

19. Mirkin KA, Luke FE, Gangi A, et al. Sarcopenia related to neoadjuvant chemotherapy and perioperative outcomes in resected gastric cancer: a multi-institutional analysis. J Gastrointest Oncol 2017; 8: 589-95.

20. Choi MH, Oh SN, Lee IK, Oh ST, Won DD. Sarcopenia is negatively associated with long-term outcomes in locally advanced rectal cancer. J Cachexia Sarcopenia Muscle 2018; 9: 53-9.

21. Tamagawa H, Aoyama T, Iguchi K, et al. Preoperative evaluation of skeletal muscle mass in the risk assessment for the short-term outcome of elderly colorectal cancer patients undergoing colectomy. Mol Clin Oncol 2018; 8: 779-84.

22. Margadant CC, Bruns ER, Sloothaak DA, et al. Lower muscle density is associated with majör postoperative complications in older patients after surgery for colorectal cancer. Eur J Surg Oncol 2016; 42: 1654-9.

23. Marimuthu K, Varadhan KK, Ljungqvist O, Lobo DN. A meta-analysis of the effect of combinations of immunemodulating nutrients on outcome in patients undergoing major open gastrointestinal surgery. Ann Surg 2012; 255: 1060-8.

24. Nakanishi R, Oki E, Sasaki S, et al. Sarcopenia is an independent predictor of complications after colorectal cancer surgery. Surg Today 2018; 48: 151-7.

25. Hajibandeh S, Hajibandeh S, Jarvis R, Bhogal T, Dalmia $S$. Meta-analysis of the effect of sarcopenia in predicting postoperative mortality in emergency and elective abdominal surgery. Surgeon 2018; 30.pii: S1479666X(18)30119-7. 